\title{
Novel Production Of Biofuels From Neem Oil
}

\author{
K.V.Radha ${ }^{1, *}$, G.Manikandan $^{1}$ \\ ${ }^{1}$ Department of chemical Engineering, Anna University, Chennai, India \\ * Corresponding author. Tel: +91 044 22359124, E-mail: radha@annauniv.edu
}

\begin{abstract}
Biodiesel production is a valuable process which needs a continued study and optimization process because of its environmentally advantageous attributes and its renewable nature. In India Neem tree is a widely grown crop, termed as Divine Tree due to its wide relevance in many areas of study. The present study is intended to consider aspects related to the feasibility of the production of biodiesel from neem oil. This report deals with biodiesel obtained from neem oil which are mono esters produced using transesterification process. The optimum conditions to achieve maximum yield of biodiesel were investigated at different temperatures and with different molar ratio of neem oil and methanol. The temperature increases yield of methyl ester at $55{ }^{\circ} \mathrm{C}$ and a molar ratio of 1:12 were found to be beneficial. From the obtained results it was apparent that the produced biodiesel fuel was within the recommended standards of biodiesel fuel. The fuel properties of biodiesel including kinematic viscosity and acid value were examined. The engine power and pollutant emissions characteristics under different biodiesel percentages were also studied. Experiments demonstrated that the biodiesel produced using neem oil could reduce smoke and Carbon monoxide emissions, significantly while the Nitrogen oxide emission changed slightly. Thus, the ester of this oil can be used as environment friendly alternative fuel for diesel engine.
\end{abstract}

Keywords: Biodiesel, Transesterification, Methyl ester of neem oil, Emissions

\section{Introduction}

Vegetable oils have become more attractive in the recent past owing to its environmental benefits and the fact that it is made from renewable resources. Vegetable oils are a renewable and potentially inexhaustible source of energy with an energetic content close to diesel fuel. Oils derived from vegetable and microbial sources may in course of time become as important as petroleum and the coal tar products of present time [1]. Recent increases in petroleum prices and due to uncertainties concerning petroleum availability, there is renewed interest in vegetable oil fuels for diesel engines [2].

Neem (Azadirachta indica) is a tree in the mahogany family Meliaceae which is abundantly grown in varied parts of India. The Neem grows on almost all types of soils including clayey, saline and alkaline conditions. Neem seed obtained from this tree are collected, de-pulped, sun dried and crushed for oil extraction. The seeds have $45 \%$ oil which has high potential for the production of biodiesel [3]. Neem oil is generally light to dark brown, bitter and has a rather strong odour that is said to combine the odours of peanut and garlic. It comprises mainly of triglycerides and large amounts of triterpenoid compounds, which are responsible for the bitter taste. It is hydrophobic in nature and in order to emulsify it in water for application purposes, it has to be formulated with appropriate surfactants.

Neem oil also contains steroids (campesterol, beta-sitosterol, stigma sterol) and a plethora of triterpenoids of which Azadirachtin is the most widely studied [4].This study is intended to consider aspects related to the feasibility of the production of biodiesel from neem oil in an attempt to produce biodiesel using the abundantly grown tree naturally as the use of vegetable oils for engine fuels seems insignificant at present day scenario. Neem oil will become a potential supplier of Biodiesel in future. Biodiesel is a mono alkyl ester (methyl or ethyl ester) of long chain fatty acids derived from renewable lipid of neem oil. Biodiesel thus obtained can be used in any compression ignition (diesel) engines without the need of modification and is therefore a good substitute for diesel fuel. The first documented commercial production of 
rapeseed oil methyl esters is reported to be in 1988 [5]. It possesses several distinct advantages over petro-diesel in following safety, biodegradability and environmental aspects [6].

This present study is intended to consider aspects related to the feasibility of the production of biodiesel from neem oil. The variables affecting the yield and characteristics of the biodiesel made were studied. The obtained results were analyzed and compared with conventional diesel fuels.

\section{Methodology}

Neem oil was obtained commercially. Chemicals such as Sodium hydroxide, Methanol, Sulphuric acid, Phosphoric acid were purchased from Merck. All the chemicals used were of analytical reagent grade.

\subsection{Experimental Setup of Transesterification Process}

Biodiesel fuel blend can be conventionally prepared by using alkali or acid as catalyst.100gm of refined neem oil is mixed with $12 \mathrm{gm}$ of alcohol and $1 \mathrm{gm}$ of sodium hydroxide $(\mathrm{NaOH})$ which acts as catalyst. The experiments were conducted in a m anner similar to Soxhlet extraction apparatus [7].This mixture is taken in a $500 \mathrm{ml}$ round bottomed flask . The amount of catalyst that should be added to the reactor varies from $0.5 \%$ to $1 \% \mathrm{w} / \mathrm{w}$. Using magnetic stirrer and heater equipment the above mixture is thoroughly mixed and maintained at a temperature of $50-55{ }^{0} \mathrm{C}$ for two hours. The mixture is now allowed to settle for 24 hours at which two separate layers are obtained. The top layer will be methyl ester of neem oil (fatty acid methyl ester (FAME) i.e, .biodiesel) and the bottom one glycerin. Using a conical separating funnel the glycerin is separated at the bottom. To separate the FAME (fatty acid methyl ester) from glycerol, catalyst $(\mathrm{NaOH})$ and methanol, washing was carried out with warm water. Further water and methanol will be removed by distillation. Then the $\mathrm{NaOH}$, Glycerol, methanol and water was treated with phosphoric acid for neutralizing the catalyst. Finally glycerin is obtained as a byproduct in case of alkali transesterification process. Fig.1. shows the experimental set up of the process.

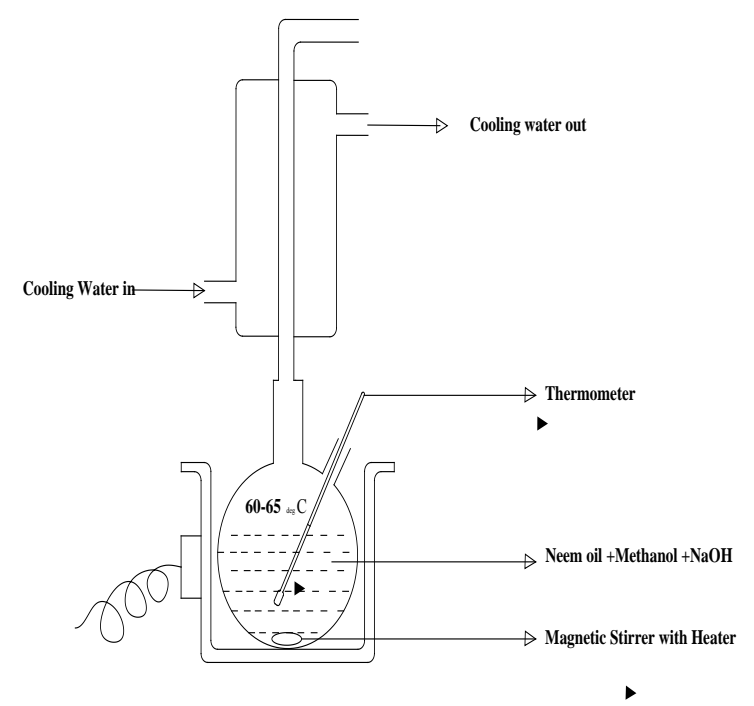

Fig.1. Experimental set-up 
Acid catalyst production is the second conventional way of making the biodiesel. The most commonly used acid is sulfuric acid. This type of catalyst gives very high yield in esters but the reaction is very slow, requiring almost always more than one day obtaining the final product [8].

\subsection{Distillation of Crude Biodiesel}

The crude biodiesel was composed of FAME and methanol. FAME was purified by a distillation system. It was provided with an evaporator and an internal condenser. Feed $(0.2$ $\mathrm{L} / \mathrm{h}$ ) was let in using a jacketed glass vessel equipped with a flow regulation valve, where the temperature was maintained at $40^{\circ} \mathrm{C}$. The discharge of distillate and residue was done in glass flasks. The vacuum system was composed of a mechanical pump and a diffusion pump. The heating of the evaporator was provided by a jacket. The yield of the purified biodiesel (FAME) was calculated by from the ratio of the mass of the purified biodiesel to that of the crude biodiesel. Biodiesel was distilled from the crude biodiesel at evaporator temperatures of $40,50,60$, and $70{ }^{\circ} \mathrm{C}$. Other conditions for distillation were maintained at evaporator vacuum to be $1.0 \mathrm{~Pa}$, the condenser temperature at $40^{\circ} \mathrm{C}$.

\section{Results and Discussion}

The raw neem oil has high moisture content and contains other impurities. In order to remove the moisture and impurities from the neem oil it has to be refined. The purification process can be accelerated tremendously by boiling the oil with about $20 \%$ of water. The boiling should continue until the water has completely evaporated (no bubbles of water vapor anymore). After few hours the oil then becomes clear. This refined neem oil is taken as raw material for transesterification process. If the neem oil is having $6 \%$ free fatty acid content alkali transesterification process seems to be better option otherwise acid transesterification process is carried out. Since the free fatty acid content was observed to be 5.7 in weight percentage alkali transesterification process was carried out. The refined neem oil was checked before doing transesterification process and properties are tabulated in Table 1.

Table 1. Properties of Neem oil

\begin{tabular}{lclc}
\hline \multicolumn{1}{c}{ Properties } & Quantity & Fatty Acid & Weight \% \\
\hline Moisture content (wt \%) & 0.4 & Oleic acid & 51.3 \\
$\begin{array}{l}\text { Free Fatty Acid Content } \\
\text { (wt \%) }\end{array}$ & 5.7 & Palmitic acid & 17.8 \\
Refractive Index & 1.47 & Linoleic acid & 14.7 \\
Gum Content (wt \%) & 0 & Steric acid & 14.4 \\
Iodine Value & 80 & Arachidic acid & 1.6 \\
Density(kg/m3) & 1024 & Myristic acid & 0.03 \\
\hline
\end{tabular}

\subsection{Transesterification process at different molar ratios of methanol and neem oil-alkali catalyst}

Different molar ratios of methanol and neem oil were taken for studying the yield percentage. The mole ratio of 1:12 was found to be efficient compared to lower or higher molar ratios where the conversion was around $83 \%$. On further increase in the methanol it leads to a 
saturation curve as shown in Fig.1 , 1: 12 molar ratio were taken for further studies. Temperature effects were conducted on transesterification process (Fig.2). As the temperatures increases, the yield of methyl ester also increases to a maximum of $92 \%$ which was at $55^{\circ} \mathrm{C}$.If the temperature reached a $\mathrm{v}$ alue beyond $60^{\circ} \mathrm{C}$ the yield started decreasing drastically.

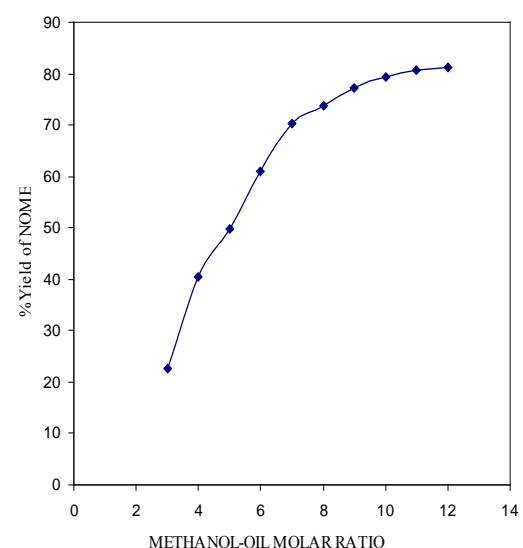

Fig.2. Different molar ratio of methanol and oil

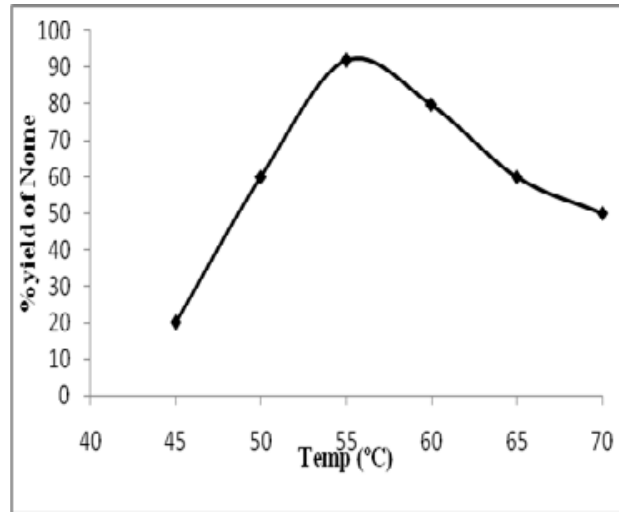

Fig. 3. Effect of temperature

Table 2. Comparison of Biodiesel obtained from acid, alkali catalysts and Commercial Diesel

\begin{tabular}{|c|c|c|c|}
\hline PROPERTIES & $\begin{array}{l}\text { NOME } \\
\text { (ACID } \\
\text { CATALYST) }\end{array}$ & $\begin{array}{l}\text { NOME } \\
\text { (ALKALI } \\
\text { CATALYST) }\end{array}$ & DIESEL FUEL \\
\hline Viscosity at $40{ }^{\circ} \mathrm{C}(\mathrm{cP})$ & 5.3 & 4.9 & 6.8 \\
\hline $\begin{array}{llll}\begin{array}{l}\text { Density } \\
(\mathrm{g} / \mathrm{cc})\end{array} & \text { at } & 15 & { }^{0} \mathrm{C} \\
& & & \end{array}$ & 0.78 & 0.81 & 0.8 \\
\hline Heating value( $\mathrm{Mj} / \mathrm{kg})$ & 39.1 & 39.4 & 44.5 \\
\hline Cetane number & 46.0 & 46.0 & 51.0 \\
\hline Carbon mass (wt \%) & 76.7 & 76.7 & 86.8 \\
\hline Hydrogen (wt \%) & 12.1 & 12.1 & 13.1 \\
\hline Oxygen (wt \%) & 11.15 & 11.15 & 0.00 \\
\hline $\mathrm{C} / \mathrm{H}$ ratio & 6.33 & 6.33 & 6.63 \\
\hline Sulphur (wt \%) & $\leq 0.004$ & $\leq 0.004$ & 0.042 \\
\hline Total glycerin $(\%)$ & 0.027 & 0.03 & - \\
\hline Free glycerin & 0 & 0.00 & - \\
\hline
\end{tabular}




\subsection{Properties of NOME}

The comparison of properties between neem oil and diesel are tabulated in Table 2.Testing was done to study the properties of the neem oil after undergoing transesterification process and properties of neem oil methyl ester is tabulated in Table 2. The cetane number was found to be 46 which are in par with commercially available diesel. Sandun Fernando et al., stated that the cetane number for biodiesel should be a minimum of 47[9]; as high cetane number could lead to engine performance problems. Glycerin result measures the amounts of unconverted and partially converted fats and oils which are in comparison in both the catalysts. The neem oil properties were compared with the normal diesel fuel. The sulphur content of NOME was found to be less than 0.004. Compared to diesel it is very less. So neem oil is found to be nontoxic.

\subsection{FTIR results of nonesterified and esterified neem oil}

The FTIR test of nonesterified and esterified neem oil is carried out using MATSEN equipment. The IR spectra of neat esterified and nonesterified neem oil show (Fig.4 \& Fig.5) the pronounced functional groups which indicate the presence of alkanes and lesser extent of aromatics and polyaromatics groups, with a clear absence of phosphorous and sulfur. The IR

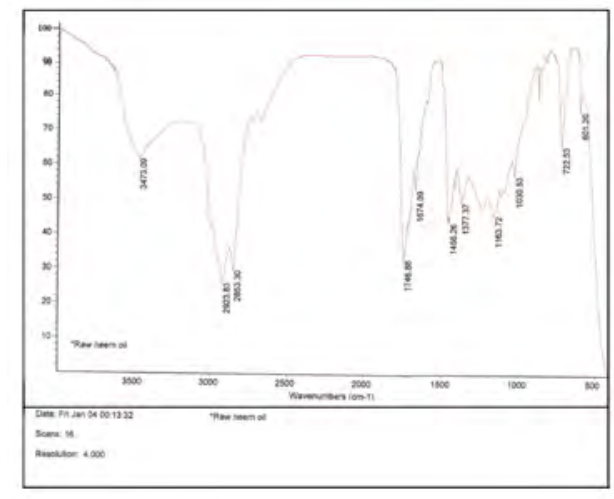

Fig.4. IR Spectra of Esterified neem oil

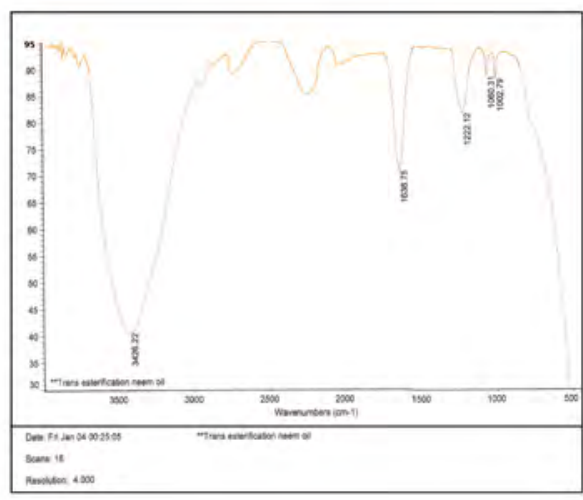

Fig. 5. IR Spectra of non Esterified neem oil

spectra of the esterified neem oil also show that they contain significant amount of esters. The esterified neem oil contains little amount of water and this water was removed by heating the oil before using in the engine. The comparative frequency ranges of IR-spectra, their corresponding functional groups and indicated compounds were performed by Nurun Nabi et al. [10].

\subsection{Distillation of Crude Biodiesel}

The yield of purified biodiesel increased as the evaporator temperature increased from 40 to $70{ }^{\circ} \mathrm{C}$, the yield increased from $55.45 \% \pm 0.5 \%$ to $63.67 \% \pm 0.25 \%$. However, the color of the final products changed from being colorless to light yellow when the evaporator temperature increased. Distillation was introduced as an alternative practice for biodiesel production via two ways. One method was to remove the FFAs from the feedstock with a high acid value to a very low extent, so the base-catalyzed transesterification was easy to perform. The other method was to purify FAME at $50-80^{\circ} \mathrm{C}$ from the crude biodiesel from low-quality feedstock to meet a high biodiesel standard. Distillation was also employed to remove FFAs from acidic neem seed oil at $60^{\circ} \mathrm{C}$ for the production of biodiesel. 


\subsection{Analysis Of Exhaust Emissions With Neat Diesel Fuel And Diesel Neem Oil Blends}

\subsubsection{Effect of engine speed on brake thermal efficiency}

In order to study the effect of Brake thermal efficiency, the speed of engine was operated at various levels ranging from 500-1500rpm. In this study, four cylinders IDI diesel engine was used as a test engine. The test engine specifications as reported by them were injection time $20^{\circ} \mathrm{CA}$ BTDC and pressure of 120 bar.

An increase in the engine speed of upto $1050 \mathrm{rpm}$ the Brake thermal efficiency increased as also the fuel consumption. Beyond 1050rpm there was a s light decrease in Brake thermal efficiency even with higher fuel consumption. This is an indication of low calorific value with an increase in fuel consumption. At 1050rpm, there was high Brake thermal efficiency indicating complete combustion of fuel hence further studies were carried out at this rpm.

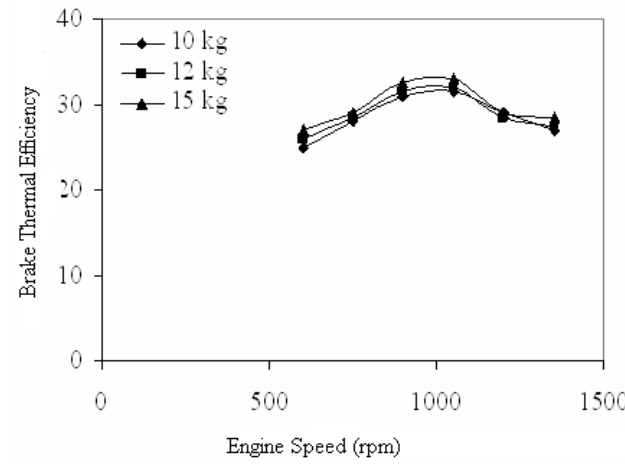

Fig.6. Brake Thermal efficiency

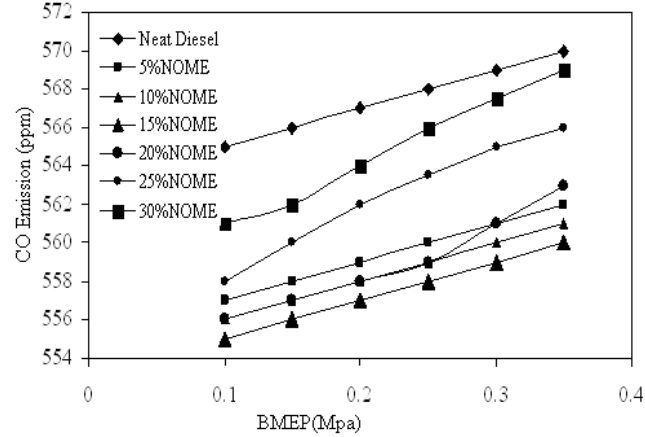

Fig. 7. Carbon monoxide emission

\subsubsection{Carbon monoxide emission}

The carbon monoxide emissions of the Neem oil methyl ester and various other blends of biodiesel were found at the rated engine speed of $1050 \mathrm{rpm}$ for different Brake Mean Effective Pressure (BMEP). The result shows (Fig.7) carbon monoxide emissions are found to be increasing with increasing BMEP. This is typical with all internal combustion engines, since air fuel ratio decreases with increase in load. The engine emits more $\mathrm{CO}$ using diesel as compared to that of biodiesel blends under all BMEP conditions. With increasing biodiesel percentage $\mathrm{CO}$ emission level decreases up to $15 \%$ blend, increasing the percentage of NOME in diesel more than $15 \% \mathrm{CO}$ emission is increases. Biodiesel itself has about $11.15 \%$ oxygen content in it. This helps for the complete combustion. Reports show that the carbon monoxide emissions emerging from the biodiesel will lower the overall load and speed ranges up to $51.6 \%[10]$.

\subsection{3. $N O_{X}$ emission}

The $\mathrm{NO}_{\mathrm{X}}$ emission characteristics with respect to various BMEP's at various blends of Neem oil was found. The result shows (Fig.8) the diesel fuel is having lower $\mathrm{NO}_{\mathrm{X}}$ emission and blended Neem oil is having higher $\mathrm{NO}_{\mathrm{X}}$ emission. Compared to conventional fuel the $\mathrm{NO}_{\mathrm{X}}$ emission is increased by $5 \%$ with the blend of Neem oil. The presence of oxygen in NOME helps to produce more amount of $\mathrm{NO}_{\mathrm{X}}$ The impact of fuel injection also play a role in the higher $\mathrm{NO}_{\mathrm{X}}$ emissions in the NOME. The NOx variations were less than $8 \%$, which is consistent with most published results [11]. 


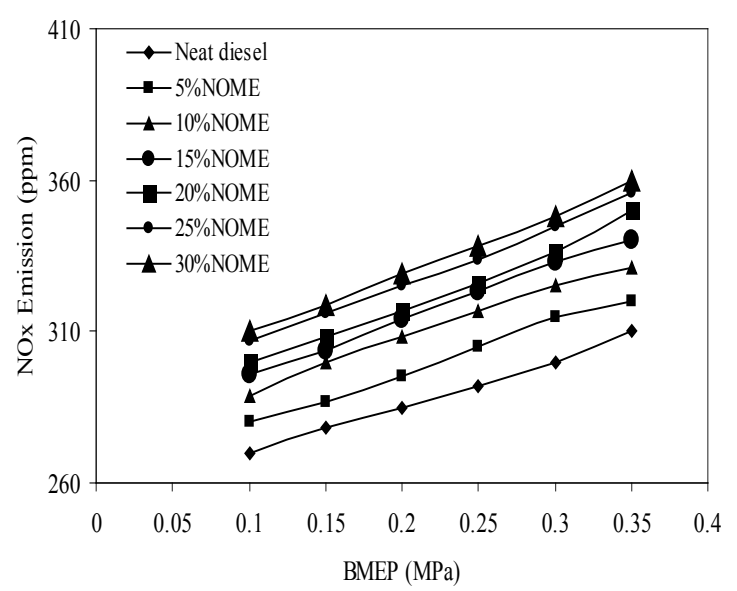

Fig.8. $\mathrm{No}_{x}$ Emission

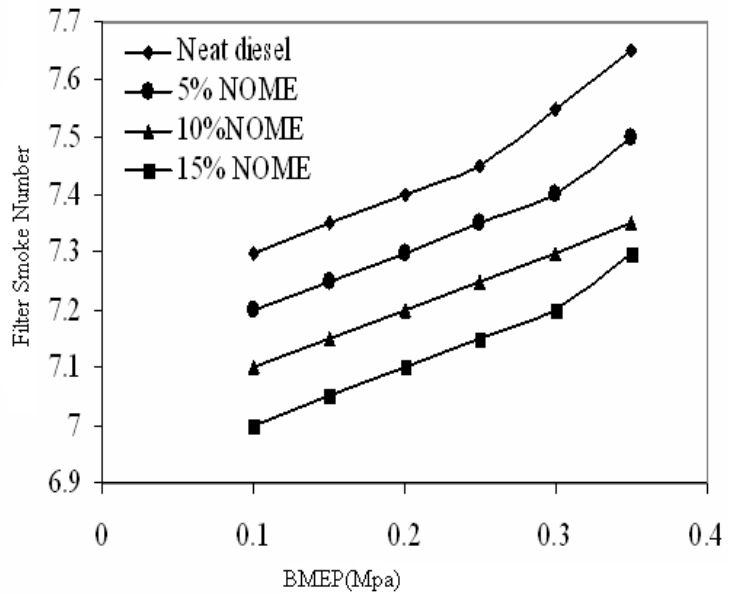

Fig. 9. Smoke emission

\subsubsection{Smoke emission}

Fig.9 represents filter smoke number with respect to different BMEP. The filter smoke number with respect to different BMEP was analyzed for various blends of fuel. The results confirm that filter smoke number for biodiesel blend to be lower for NOME than that of the diesel fuel. $15 \%$ blend show low smoke number contributing to the factor that lesser amount of unburnt hydrocarbons is present in the engine exhaust emission. Previous researchers showed the visible smoke emerging from the biodiesel over all load and speed ranges are lower by $13.5 \%$ to $60.3 \%$ [12].

\section{Conclusion}

Studies have been made using neem oil, a novel feedstock of obtaining biodiesel which is renewable in nature. The effect of methanol to oil molar ratio and acid \& alkali catalyst transesterification were analyzed. The exhaust emissions of neem oil blended biodiesel are studied. Compared with conventional diesel fuel, diesel exhaust emissions including smoke and $\mathrm{CO}$ were reduced, while $\mathrm{NO}_{\mathrm{X}}$ emission was increased with the diesel-NOME blends. The reductions in $\mathrm{CO}$ and smoke emissions and the increase in $\mathrm{NO}_{\mathrm{X}}$ emission with Diesel NOME blends may be associated with the oxygen content in the fuel. More than $15 \%$ NOMEdiesel blends created poor atomization tendency and incomplete combustion in engine. So the engine exhaust emission level is increased. The ester of this oil can be used as environment friendly alternative fuel for diesel engine creating a greener environment in the future.

\section{References}

[1] Ganguli, S. (2002) 'Neem: A therapeutic for all seasons', Current Science, Vol. 82, pp.1304.

[2] Mishra, A.K., Singh, N. and Sharma, V.P. (1995) 'Use of neem oil as a mosquito repellent in tribal villages of mandla district', Indian J Malariol, Vol.3, pp.99-103.

[3] M.A. Fazal, A.S.M.A. Haseeb and H.H. Masjuki .(2011) 'Biodiesel feasibility study: An evaluation of material compatibility; performance; emission and engine durability',Renew. sustain.Engy Reviews, Vol.15,2, 1314-1324.

[4] Foglia, T.A., Jones, K.C., Haas, M.J. and Scott, K.M. (2000) 'Technologies supporting the adoption of biodiesel as an alternative fuel. The cotton gin and oil mill presses.

[5] Fukuda, H., Kondo, A. and Noda, H. (2001) 'Biodiesel fuel production by transesterification of oils', J Biosci Bioeng, Vol.5, pp. 405-416. 
[6] Barnwal, B.K. and Sharma, M.P. (2005) 'Prospects of Biodiesel production from vegetable oils in India', Renew Sust Energy Rev 9, Vol.4, pp. 363-378.

[7] Mittelbach, M. and Tratnigg, B. (1990) 'Kinetics of alkaline catalyzed methanolysis of sunflower oil', Fat Sci Technol, Vol.4, pp.145-148.

[8] Sandun Fernando., Prashanth Karra., Rafael Hernandez and Saroj kumar jha. (2007) 'Effect of incompletely converted soyabean oil on bi odiesel quality'Energy, Vol.32, pp.844-851.

[9] Nurun nabi, Md.,Shamim Akhter.,Mhia Md and Zaglul Shahadat. (2006) 'Improvement of engine emissions with conventional diesel fuel and diesel-biodiesel blends', Bioresource technology, Vol.97, pp.372-378.

[10]. Anjana Srivastava and Ram Prasad. (2004) 'Triglycerides based diesel fuels', Renewable and sustainable energy reviews, Vol.4, pp.111-133.

[11] Sahoo, P.K.,Das, L.M,Babu., M.K.G. and Naik, S.N. (2007) 'Biodiesel development from high acid value polanga seed oil and performance evaluation in a CI engine', Bioresorce Technology,Vol.86,pp.448-454.

[12] Gvidonas Labeckas and Stasys Slavinskas. (2006) 'The effect of rapeseed methyl ester in direct injection diesel engine performance and exhaust emissions',Energy conversion and Management,Vol.47,pp.1954-1967.

[13] Carmen María Fernández, María Jesús Ramos, Ángel Pérez and Juan Francisco Rodríguez, (2010)'Production of biodiesel from winery waste: Extraction, refining and transesterificationofgrapeseedoil,Biores.Technol.Vol.101,18, pp.7019-7024 